\title{
Editorials
}

\section{Burnout and empathy in primary care:}

\author{
three hypotheses
}

\section{THE IMPORTANCE OF EMPATHY IN PRIMARY CARE}

In the last 10 years, a growing literature about empathy in primary care indicates that, for both patient and clinician, empathy helps to improve many aspects of health care practice and patient satisfaction. Wensing et al' indicated that humaneness, exploring the needs of patients, and good communication skills are some of the high priorities that patients expect from their GP. Cape et al showed that doctor empathy coded by external observers was positively correlated with listening interactions and patient involvement. Vedsted and $\mathrm{Heje}^{3}$ found that patients tended to recommend their GP to others if they judged them as 'empathic'. Mercer et al ${ }^{4}$ showed a positive relationship both between GP empathy and patient enablement at the consultation, and between patient enablement and changes in the main symptom and well-being evaluated 3 months after the consultation. Finally, Verheul et al investigated the impact of a warm and empathic consultation compared to a cold and formal consultation on the certainty of the outcome. The greatest beneficial effects of empathic communication on stress reduction and expectancies were observed when it was combined with a positive expectations style.

To preserve effective empathy in care, the health provider must be in a positive frame of mind and not affected by stress or burnout. Burnout occurs when individuals feel emotionally overwhelmed by the demands of their job. Physicians in particular are frequently overloaded with the demands of caring for sick patients within the constraints of time and resources.

\section{HYPOTHESIS ONE: BURNOUT IS AN EMPATHY KILLER}

The prevalence of burnout in GPs is well known: about one in three has experienced exhaustion and burnout in Europe and the US. The level of burnout in GPs may depend on several factors, such as participation in a peer group or continuing medical education. Among GPs, burnout has negative effects, from impaired job performance to suicide, while an increasing amount of data suggest potential direct links between empathy and burnout. 6.7
Burnout is in part defined by a depersonalisation attitude: it favours dehumanisation in social interactions, and probably a significant decrease of overall empathy. Hence, burnout appears to be as toxic for the clinician as for the patient. ${ }^{8}$ Exhausted GPs will be less able to stand in the patient's shoes and listen emphatically, and would prefer to protect themselves by putting the patients at a distance and depersonalising them. Brazeau et $a^{6}$ observed that the higher the level of medical student's burnout, the lower their clinical empathy. Zenasni et al observed the same results with GPs in practice. As emphasised by Truchot, ${ }^{9}$ when GPs are at a high level of burnout, they tend to withdraw from the relationships with patients. This withdrawal strategy allows the health providers in burnout to restore a sense of psychological balance or protection of their internal resources.

\section{HYPOTHESIS TWO: EMPATHY CREATES BURNOUT}

If evidence shows that burnout hampers empathy, the reverse effect of empathy on burnout is less clear. One assumption is that a high level of empathy may cause 'compassion fatigue' and then create exhaustion and burnout. According to Nielsen and Tulinius, ${ }^{10}$ compassion fatigue in general practice refers to being exhausted emotionally' due to frequent difficult patient encounters, associated with the need for great attention and empathic listening. Figley" ${ }^{11}$ analysed this experience of compassion fatigue and defined it as an extreme state of tension and preoccupation with the suffering of those being helped to the degree that it is traumatising for the professional. Compassion stress, that is stress connected with exposure to a sufferer, may then occur. However, this view relies on a specific definition of empathy that emphasises affective aspects. One inappropriate consequence of empathy is that the physician may become too subjected to the feelings of the patient and could consequently suggest inappropriate compassionate care. However, if a certain type of empathy may clearly lead to exhaustion and burnout, we also need to consider that an optimal empathic posture may, to the contrary, alleviate stress and burnout.

\section{HYPOTHESIS THREE: EMPATHY PREVENTS BURNOUT}

It is suggested that empathy may protect health providers from burnout. Halpern ${ }^{12}$ considers that empathy would be associated with satisfaction at work for the provider and help them find meaning in their professional activity. She suggests that, instead of a complete detachment strategy, physicians need to 'practice' an emotional attunement that is practised with clinical empathy. Being empathic supposes awareness of negative emotions, and requires the physician to practice selfreflection, and to accept negative feedback; these skills are resources against stress and burnout. Therefore, helping health providers to be more empathic will help to protect them from burnout. Halpern reminds us that emotionally engaged physicians have greater therapeutic efficacy and tend to experience better work satisfaction and self-accomplishment.

\section{DIFFERENT KINDS OF EMPATHY}

These apparently conflicting effects of empathy suggest that different empathic approaches could yield different outcomes in primary care. Different kinds of empathy have differential effects and may interact with each other, which may explain the distinct hypotheses/effects proposed above. $^{13}$
"Helping health providers to be more empathic will help to protect them from burnout. Halpern reminds us that emotionally engaged physicians have greater therapeutic efficacy and tend to experience better work satisfaction and self-accomplishment. 
There is a consensus on separating cognitive and affective empathy. The first suggests that the physician recognises the patients' ongoing personal experience, mental states, or motivation. The second supposes that the physician experiences the same feeling that the patient. Additional styles of empathy were identified during psychotherapy and general practice: sharing and nurturant empathies. ${ }^{14,15}$ In the sharing empathy style, the health professional shares some opinions and intervenes to comment some action or thoughts of the clients. The nurturant empathy supposes that the professional is attentive and provides attention and security to the patient.

It has been suggested that the optimal empathic approach for physicians should be 'clinical empathy', preventing them from reaching a too compassionate or sympathetic position, without ignoring the emotional reaction and feeling of the patients. As defined by Hojat et al, ${ }^{16}$ clinical empathy is primarily a cognitive quality that involves an understanding of the inner experiences and perspectives of the patient as a separate individual, combined with a capability to communicate this understanding to the patient. However, as suggested by Halpern, clinical empathy should not refer to a complete avoidance of both emotion and affective empathy, but a complex/global cognitive and affective approach. It is still unclear to what degree is affective empathy necessary for clinical empathy to occur, and the level to which it becomes inappropriate in the caring relationship. In any case, clinical empathy must involve the ability to distinguish the self from the other in order not to be misplaced in the patient's pain and emotions. This will guard against longer-term exhaustion and depersonalisation, and help to prevent burnout. ${ }^{17}$

\section{Franck Zenasni,}

Assistant Professor, Université Paris Descartes, Sorbonne Paris Cité, IUPDP, Boulogne-Billancourt, France.

\section{Emilie Boujut,}

Assistant Professor, Université Paris Descartes, Sorbonne Paris Cité, IUPDP, Boulogne-Billancourt, France.

\section{Aude Woerner,}

Medical Resident, Université Paris Descartes, Sorbonne Paris Cité, General Medecine Department, Paris, France.

\section{Serge Sultan,}

Associate Professor and Senior Researcher, Université de Montréal, CHU Sainte-Justine, Montréal, Quebec, Canada.

\section{Competing interests}

This paper received support from Sanofi-Aventis through an investigator-initiated operational grant. The authors have declared no other competing interests.

DOI: 10.3399/bjgp12X652193

\section{REFERENCES}

1. Wensing M, Jung HP, Mainz J, et al. A systematic review of the literature on patient priorities for general practice care. Part 1 : Description of the research domain. Soc Sci Med 1998; 47(10): 1573-1588

2. Cape J, Barker C, Buszewicz M, Pistrang N. General practitioner psychological management of common emotional problems (II): A research agenda for the development of evidence-based practice. Br J Gen Pract 2000 50(454): 396-400.

3. Vedsted P, Heje HN. Association between patients' recommendation of their GP and their evaluation of the GP. Scand J Prim Health Care 2008; 26(4): 228-234.

4. Mercer SW, Neumann M, Wirtz M, et al. General practitioner empathy, patient enablement, and patient-reported outcomes in primary care in an area of high socioeconomic deprivation in Scotland. Patient Educ Couns 2008; 73(2): 240-245.

5. Verheul W, Sanders A, Bensing J. The effects of physicians' affect-oriented communication style and raising expectations on analogue patients' anxiety, affect and expectancies. Patient Educ Couns 2010; 80(3): 300-306.

6. Brazeau CM, Schroeder R, Rovi S, Boyd L. Relationships between medical student burnout, empathy, and professionalism climate. Acad Med 2010; 85(10 Suppl): 33-36.

7. Zenasni F, Boujut E, Bluffel du Vaure C, CatuPinault $A$, et al. Development of a Frenchlanguage version of the Jefferson Scale of Physician Empathy and association with practice characteristics and burnout in a sample of general practitioners. Int J Pers Cent Med [in press].

8. Shanafelt TD, West C, Zhao X, et al. Relationship between increased personal well-being and enhanced empathy among internal medicine residents. J Gen Intern Med

\section{ADDRESS FOR CORRESPONDENCE}

\section{Franck Zenasn}

Université Paris Descartes, Psychology, 71 avenue Edouard Vaillant, Paris, 92100, France.

\section{E-mail: franck.zenasnidgmail.com}

\section{5; 20(7): 559-564}

9. Truchot D, Roncari N, Bantégnie D. [Burnout, patient compliance and psychological withdrawal among GPs: an exploratory study] Burn out, compliance du patient et retrait psychologique chez les médecins généralistes: une étude exploratoire. L'encéphale 2011; 37(1): 48-53.

10. Nielsen $H G$, Tulinius $C$. Preventing burnout among general practitioners: is there a possible route? Educ Prim Care 2009; 20(5): 353-359.

11. Figley CR. Compassion fatigue: toward a new understanding of the costs of caring. In: Hudnall Stamm B (ed.). Secondary traumatic stress: self-care issues for clinicians, researchers, and educators. Lutherville, MD: Sidran Press, 1995.

12. Halpern J. What is clinical empathy? J Gen Intern Med 2003; 18(8): 670-674

13. Lelorain S, Brédart A, Dolbeault S, Sultan S. A systematic review of the associations between empathy measures and patient outcomes in cancer care. Psychooncology 2012; DOI: 10.1002/pon.2115.

14. Bachelor A. How clients perceive therapist empathy: a content analysis of 'received' empathy. Psychotherapy: Theory, Research and Practice 1988; 25(2): 227-240.

15. Wynn R. Empathy in general practice consultations: a qualitative analysis. Epidemiol Psichiatr Soc 2005; 14(3): 163-169.

16. Hojat M, Gonnella JS, Nasca TJ, et al. Physician empathy: definition, components, measurement, and relationship to gender and specialty. Am J Psychiatry 2002; 159(9): 1563-1569.

17. Decety J, Yang CY, Cheng Y. Physicians downregulate their pain empathy response: An event-related brain potential study. Neuroimage 2010; 50(4): 873-882. 